\title{
ASSESSING THE ACCESSIBILITY OF THE HOMEOWNERSHIP MARKET
}

\author{
Dirk Brounen and Peter Neuteboom \\ Rotterdam School of Management \\ Erasmus University Rotterdam
}

Brounen is Professor of Finance and Real Estate, Neuteboom is Assistant Professor of Real Estate, both at the Finance Group of the Rotterdam School of Management at Erasmus University Rotterdam, the Netherlands. The authors thank the Dutch Ministry of Housing for providing the data. The authors also thank all participants of the 2006 Rotterdam Housing Symposium 2006, the participants of the Annual Meeting of the European Real Estate Society (ERES) in Weimar 2006, participants of the Annual Conference of the European Network of Housing Researchers (ENHR) in Prague for valuable feedback on previous versions of this paper. Contact Details: Burgemeester Oudlaan 50, Rotterdam, the Netherlands Email: pneuteboom@rsm.nl, Tel. +31 (0)10 - 4081276 
Page $\mid 2$ 


\title{
ASSESSING THE ACCESSIBILITY OF THE HOMEOWNERSHIP MARKET
}

\author{
Abstract \\ In this paper, we examine the accessibility of the homeownership market using \\ measures that include both supply and demand characteristics of regional \\ housing markets. We apply these measures empirically on an extensive data set \\ that covers the Dutch housing market. \\ Our analysis quantifies the extent to which the position of new entrants of the \\ homeownership market, the first-time buyers, has weakened over the sample \\ period and we identify which factors are driving this change. We find that due \\ to financial constraints of young households smaller portions of the housing \\ market are becoming affordable. However, more importantly, we report that \\ first-time buyers today need to contend with a much larger group of \\ competing bidders on every house that suits their financial situation, than ever \\ before. \\ Keywords: First-time buyers, affordability, competition, homeownership market
}




\section{ASSESSING THE ACCESSIBILITY OF THE HOMEOWNERSHIP MARKET}

\section{INTRODUCTION}

Over the last twenty years, the Dutch housing has gone through turbulent times. Since 1990, Dutch houses more than tripled a price as a result of decreasing interest rates, financial liberalization and increasing demand. Although households' income has risen as well during that period, there is growing concern that successive house price increases, have made the homeownership sector inaccessible for only but a few. While the fundamental factors underlying this trend were more generic, regional difference could be witnessed as well, with rather low opportunities for first-time buyers entering the urbanized Western part of the Netherlands (Renes et al., 2006), a situation that received broad public and political discern. Discerns that were quickly followed by a call for - or initiatives to - specific measures to assist first-time buyers.

Besides the direct problems inaccessibility of homeownership markets may cause for prospective homeowners, the impact for the market might be potentially far greater. After all, the inflow of first-time buyers is vital for the overall health of the housing market. First-time buyers propel the blood circulation in the housing market by creating the necessary liquidity at the lower end of the market. A slowdown in these segments of the housing market - due to financial limitations or softening labour markets - will eventually echo into other segments of the housing market as well. On the other hand, low accessibility of housing for first-time buyers should not be exaggerated. It is inherent to the functioning of the homeownership market that outsiders, in this case the firsttime buyers, have a relatively inferior position on the housing market, because their 'purchasing 
power' is - by the general lack of home equity - often low compared to the insiders that already own their home. However, as time progress, their restrained position will be gradually lifted.

To date, the literature on first-time buyers consists of two main views. One strand of studies (e.g. Haurin et al., 1994; Bourassa et al., 1994 and Andrew and Meen 2003) stresses the importance of the relationships between tenure choice and household formation when analyzing the housing decisions of young adults. They found that wealth, the relative cost of homeownership, and various demographic variables are the main drivers of tenure choice amongst young households. Later Ásberg (1999) and Ortaglo-Magne and Rady (1999) provided more evidence; moreover, homeownership rates amongst young households turned out to be very sensitive to changes in the systems of housing provision. A second line of studies (e.g. Boehm, 1993; Engelhardt, 1994 and Haurin et al., 1997) focuses on the financial aspects in the first-time buyers' decisions. Starting with Weicher (1977 and 1978) methods and ratios were developed, that illustrated the extent to which young households were being priced out of the housing market. Initially, simply by correcting nominal house price levels for the contemporaneous development of income, and later by incorporating both mortgage interest rates and household equity. Linneman and Megbolugbe (1992), Hancock (1993) and Bourassa (1996) and Bogdon and Can (1997), Quigley and Rafael (2004) and Paris (2007) later refined this line of research. Their work showed that housing affordability is never a broad issue for the whole housing market - if so, it would only induce house prices to decrease; however, specific household categories, for instance first-time buyers, may be more at 'risk' and eventually might destabilize housing markets.

This paper adds to the existing literature by following a more 'market-orientated' approach, i.e. a new approach in assessing the accessibility of the homeownership sector for first-time buyers. The studies discussed above all focus exclusively on demand side factors, by estimating the cost of homeownership relative to income. We intend to go one step further by assessing not only demand side factors, but we also take into account the availability of dwellings on offer as well as the level of competition between prospective buyers. We apply our approach to test empirically the position of first-time buyers on the Dutch housing market for the period 1985 to 2006. This

Page $\mid 5$ 
analysis enables us to assess the accessibility of the homeownership sector for first-time buyers in the current market. But, more importantly, we are able to analyse the main drivers of the (in)accessibility of the homeownership sector.

The paper proceeds as follows. In the next section, we briefly discuss the Dutch housing market and introduce the data set that we use for our research; here we also focus on contemporary developments and the changing position of first-time buyers. In the following section, we introduce the concept of accessibility and sketch our methodology to measure this. We than continue with the results of our analysis, i.e. assessing the accessibility of the housing market for first-time buyers. We summarize and discuss our most important findings in the concluding section.

\section{The Dutch Housing MARKET}

\section{Contemporary developments}

Over the last decades, the Dutch housing market and been off balance most of time. Both demand and supply side factors contribute to these developments. Here we briefly summarize the main drivers of change and the housing market outcome; see Boelhouwer $(2002,2005)$ for a more extensive discussion of these trends and issues.

On the demand side, net real income growth (1985-2006: 177 percent), all-time low interest rates (1991: 9.23 percent vs. 4.37 percent in 2006), financial liberalisation (MOW, 2003) and a high growth in the number of households due to individualisation and immigration, have fuelled demand twofold. Firstly, the proportion of homeowners increased from 42 percent in 1985 to 54 percent in 2006 and secondly, homeowners witnessed a significant enlargement of their maximum loan capacity. Both factors resulted in higher demand in terms of quality and a shift in tenure choice away from the rental sector. Note that one may observe these trends in other European countries as well. 
On the supply side, two other trends are noticeable. Firstly, a reduction in the annual number of newly built houses only 72-thousand newly developed homes in 2006, equalling 1.1 percent of the housing stock, and secondly, higher turnover on the housing market, i.e. higher number of housing transactions.

The combination of these trends in demand and supply resulted in an unprecedented increase in house prices - nominal house prices rose over the period 1985 - 2006 with 371 percent; thereby putting pressure on the affordability, and hence, accessibility of the homeownership market for first-time buyers. Finally note that - notwithstanding Governments statements' of the contrary Dutch housing policies are geared towards promoting homeownership. Here, the main instrument is the mortgage interest tax deductibility. This fiscal facility offers homeowners the ability to deduct the interest paid at marginal tax rates; which is 52 percent from all income in excess of $€ 54.000$, while the average tax deductibility measures approx. 37 percent.

\section{Our data}

For our empirical analysis, we employ a unique household survey panel dataset, which brings in information on both household characteristics including income and dwelling characteristics including price and location. We analyse the data sets for the years 1985, 1995 and 2006, which offers us on aggregate around 230.000 observations. Moreover, the survey offers insight in the mobility of households and household members, both actual and intended, for a specified time; see Department of Housing (2006) for a further elaboration on this survey.

From the Housing need survey's we can derive both demand and the greater part of supply. Additional statistics are used to estimate the number of vacant dwellings and unsold newly built dwellings. Jointly, they give the necessary information on both housing demand and supply in a housing market during a specified time $\operatorname{span}^{1}$. In the analysis, we distinguish between stayers movers - first-time buyers, which we subdivide in former tenants and/or starters, and non-

\footnotetext{
${ }^{1}$ To prevent problems attaché to low number of cases, we defined the group buyers as household that purchased their house 2 years prior to the survey.
} 
successful buyers. Note that only households that are active on the housing market are taken into account; households that 'voluntarily' withdraw from the housing market because they assess their chances for success minimal, are not encountered for.

\section{First-time buyers, a closer look}

Before we start our analysis, we will give a description of first-time buyers on the Dutch housing market: who are they?, and what are the financial obligations they are committed to? Here the analysis is limited to households that made the first start on the homeownership market in either 2005 or 2006; to put their financial commitments and overall position in perspective, we compare them with other household categories in the rental and owner-occupied sector.

During 2005 and 2006 more than 342-thousand were able to start on the housing market, the vast majority of them started in the rental sector (77 percent vs. 23 percent). In addition, some 181thousands households moved during these years from the rental sector to the homeownership market; hence, the total number of first-time buyers was approx. 259-thousand. On the other hand, just over 79 thousand households were unsuccessful, i.e. they were willing to buy, but did not succeed. The profile of first-time buyers in both the rental and homeownership sector is rather straightforward. Starters on the rental market are mostly older than 25 years, have a low net income, while few of them have a high education; finally, they are mostly single. First-time buyers in general, are relatively older (33 years), earn higher incomes (€ 2,732), have higher education (43.4 percent), and in terms of household type, the majority consist of families without children (46.4 percent). First-time buyers, however, form a combination of first-time buyers' sec and households that move from the rental market to the homeownership sector. Both have their own clearly identifiable profile, as might be expected. The latter category consist of households that appear to be relatively older (34 vs. 29 years), have higher incomes than 'real' starters (€ 2,860 vs. $€ 2,438)$ and are more often singles (35.5 vs. 24.4 percent). This outcome is, obviously, not unexpected: the housing position of households is closely linked to labour market and household careers of those involved.

Page 18 
In Table 1 presents the financial obligations households have committed themselves too. The statistics show that during 2006 first-time buyers had to cope with significantly more housing costs than other homeowners. In the Dutch context, high loan to value ratios are common; actually, first-time buyers do not need to put up any savings to finance their purchase, since the loan to value ratio is limited to 125 percent. Loan to income ratios may be as high as four time's gross household income. In fact, in the Dutch mortgage market the only credit constraint is a maximum of the housing expenditure ratio to 35 percent. It all leads to significantly higher average net expenditure ratios for first time buyers compared to other homeowners. But again, still, these levels are significantly lower than for many households in the rental sector.

The accessibility of the homeownership market is partly based on the affordability of the dwellings on offer on the market. Both concepts - accessibility and affordability - are not synonymous, as we will discuss later in this paper. To give some preliminary insight in the affordability of homeownership we show in Figure 1 two distributions. The first one shows the distribution of house prices of dwellings on sale ${ }^{2}$, while the second distribution shows the maximum loan capacity $^{3}$ for households that were on the market for an owner-occupied dwelling for the first time. It is clear from Figure 1 that both distributions for the year 2006 do not match. In fact, for some $8 \%$ of all households their maximum loan capacity falls short for all dwellings on offer; i.e. this group will not succeed on the homeownership market whatsoever. On the other hand, for many proposed first-time buyers Figure 1 shows that there seems to be enough houses available. Of course, this type of analysis ignores timing, quality, personal preferences, and most importantly regional variations in the affordability of housing. Issues we will resolve in our approach, which will be discussed in the next section.

\footnotetext{
${ }^{2}$ Note that these houses are not reflecting the overall housing stock in terms of prices and quality: the most courant houses are the least courant!

${ }^{3}$ The maximum loan capacity is based on the income of households, the mortgage interest rate and the typical mortgage products Dutch households are taking up (i.e. savings and interest only).
} 


\section{METHODOLOGY}

\section{Introduction}

In our view, accessibility of the homeownership depends on two coherent, but distinct, concepts: affordability and competiveness. The first one is well-known in the literature and needs no further discussion; affordability refers to the purchasing capacity of households given their own income position. The concept competiveness refers to the degree of competition between households for those affordable dwellings. Essentially, this indicator informs us whether the amount of housing on offer is sufficient, given the demand for them. Here, high competition reflects a general lack of supply on the housing market and vice versa. In an efficient market, a high degree of competition will drive up house prices, and hence, lower the affordability ratio. On the other hand, low affordability will push out some customers from the market - certainly if there is a competitive alternative, i.e. the rental market -, and hence, opposing movements might occur as well. In short, both concepts mirror one side of accessibility of the housing market: affordability reflects the demand side (purchasing capacity of households) while competiveness reflects the supply side (dwellings on offer in relation to demand).

\section{The Conceptual Model}

In order to measure the accessibility of the homeownership market for new entrants, we developed two indicators that, together, capture the concept 'accessibility'. First, an indicator that shows the share of houses that is affordable for a specific household; we call this the affordability ratio. The affordability ratio, in one way or another, has appeared frequently in the literature. Here we extend this more common used ratio by incorporating different mortgage choices by (prospective) homeowners, additional costs and non-fiscal subsidies as well. Second, we used an indicator showing the competiveness on the housing market; i.e. this indicator shows the number of households thus competing for the same house. Therefore, accessibility is the joint result of the prevailing market conditions and specific household's characteristics.

Page $\mid 10$ 
In panel A of Figure 2, both indicators are presented schematically. Thhe grey line represents a frequency distribution of households and the black line represents the house price distribution of dwellings on offer on the housing market. When introducing a household $I$ with a specific income level into this framework, panel A shows us that overlapping section $\mathrm{ABC}$ represents the share of all houses on offer which are affordable for this household $I$. At the same time, household $I$ cannot choose in isolation, since their set of houses affordable, $\mathrm{ABC}$, is also affordable for other households that are present in the distribution and are looking for a new home. First, household $I$ will not need to compete with all households in the section CDEA, the total set of households that will be in the market for the affordable houses in ABC. Moreover, since some households with a better financial position might have a smaller appetite for housing, household I will also need to compete for houses in section $\mathrm{ABC}$ with households that earn more than they do. However, all dwellings with housing costs below a certain threshold are considered affordable; we do not assume that a household is actually on the market for all of these. Housing costs represent also an implicit quality level and we assume that households to not compete for dwellings well below their financial possibilities. In the graph we set a cut-off point of households wealthier than household $I$, which will be part of their competition, resulting in the total population of CDFG. In other words, in this example household $I$ will be looking for a home in the set ABC, while competing for these homes with households in the set CDFG. The number of competitors limits the chances of success of household $I$ on the housing market; hence determining the accessibility of the homeownership market. This chance can be depicted in Figure 2A by dividing the affordable share of housing stock, $\mathrm{ABC}$, by the portion of households that are in the position to compete for the same houses, CDFG.

The combination of both indicators can be used to typify the prevailing market conditions for specific groups of buyers, by simply identifying their specific income distribution. For instance, for first-time buyers in panel B, because of their relatively low level of income there is only a low affordability ratio (i.e. a low number of dwellings that is affordable for households) and high level of competition leads to an inaccessible housing market for new entrants while the opposite lead to

Page $\mid 11$ 
high accessibility, as depicted in the middle figure (labelled "B"). Alternatively, other categories on the housing market - like recent buyers - have more opportunities, as depicted in the bottom figure (labelled "C"); for those households a large share of the housing market is accessible, while competiveness is relatively low.

\section{The Econometrical Model}

We define the expenditure ratio as the ratio of net housing costs to net household income:

$$
\begin{aligned}
& b c i_{r, d, s}=f(P, i, c, Y)=\frac{l t v \cdot P \cdot i(1-\tau[Y])+c_{1}+c_{2}}{Y(1-\tau[Y])} \\
& r=1 . . R ; d=1 . . D ; s=1 . . S ; S \geq D
\end{aligned}
$$

Here $p$ stands for the house price, $i(1-\tau[Y])$ for the after-tax mortgage interest rate, $c_{1}$ for the yearly repayments (depending on mortgage type), $c_{2}$ for other housing costs (e.g. insurances, taxes, maintenance etc.), and $Y(1-\tau[Y])$ is the net household income. The subscripts $r, d$ and $s$ refer to the region (i.e. the housing market), the household characteristics of a homeowner (e.g. income) and the characteristics of the dwelling on sale (e.g. house price).

A house is assumed affordable if $h c i_{r, d, s} \leq \delta_{b}$ holds, i.e. the housing costs are lower than $\delta_{b}$ percent of net household income. The affordability ratio $\left(a f f_{r, d}\right)$ for a (potential) homeowner $d$ in region $r$ can be calculated as:

$$
\begin{aligned}
& \text { aff } f_{r, d}=\sum_{s=1}^{S}\left[\begin{array}{ll}
1 & \text { if } \quad h i_{r, d, s} \leq \delta_{b} \\
0 & \text { otherwise }
\end{array}\right] / S_{r} \\
& 0 \leq a f f_{r, d} \leq 1
\end{aligned}
$$


In other words ${ }^{4}$, aff $r, d$ represents the number of affordable dwellings on sale for a specific homeowner $d$ in region $r$ to the total number of dwellings on sale $S_{r}$ in a specific region $r$.

The competiveness indicator $\left(\operatorname{com}_{r, d}\right)$ can be defined as the number of households competing for the same house, or more precise, competing for the same set of houses; the competiveness indicator is equal to the number of unique competitors that compete for all houses affordable for household $\bar{d}$ :

$$
\begin{aligned}
& \operatorname{com}_{r, d}=\left[\sum_{s=1}^{s} a f f_{r, d, s}\left[\sum_{d=1}^{D} a f_{r, d, s}^{*}\right]\right] /\left[S_{r} A f f_{r, d}\right] \\
& a f f_{r, d, s}=\left[\begin{array}{ll}
1 & \text { if } \quad b i_{r, \bar{d}, s} \leq \delta_{b} \\
0 & \text { otherwise }
\end{array}\right] \\
& a f f_{r, d, s}^{*}=\left[\begin{array}{ll}
1 & \text { if } \quad \delta_{l} \leq h i_{r, \bar{d}, s} \leq \delta_{b} \quad \text { and } \quad d \notin C O M \\
0 & \text { otherwise }
\end{array}\right]
\end{aligned}
$$

Here we assume that not each competitor is on the market for all houses affordable. I.e. we presuppose that houses which are relatively cheap compared to his/her income, encompass less quality than preferred; hence, $\delta_{l} \leq h c i_{r, \bar{d}, s} \leq \delta_{b}$. Note that normally com ${ }_{r, d}$ will represents the upper limit of competition on the (local) housing market since differences in preferences of households in terms of quality, and exact timing - are not accounted for in the model.

We may expect that both indicators do depend heavily on time (e.g. economic cycle) as well as the prevailing housing market conditions. At times, when the economy is booming, competition will

\footnotetext{
${ }^{4}$ Note, that the subscript $t$, representing the time-dimension is left out in the above presented model(s), to keep the analysis more comprehensible. In the empirical results presented later in this paper the time-dimension is, of course, taken into account.

5 Note that the set of affordable houses depends on household's characteristics of both the individual household and of his competitors. Normally, this will lead to only partly overlapping segments of the housing market affordable for both (i.e. the individual household and/or his competitors).
} 
increase, which might tighten the housing market and eventually lower affordability ratios. Furthermore, the regional level of analysis and the hurdle rate $\left(\delta_{l}, \delta_{b}\right)$ are very important parameters in our model. When the latter is reduced, the affordability ratio is lower; while a higher regional level will not interfere much with affordability since prices tend to be distributed rather evenly across geographic submarkets. Increasing the geographic level does, however, increases the competiveness on the housing market. In the following analysis, we examine accessibility on a housing market level; in the Dutch context, 31 different regional housing markets were utilised. Finally, the top hurdle rate $\delta_{b}$ was set to 35 percent, which is the high end at which Dutch banks allow clients to finance their housing plans; we assume that household do not compete for houses, which costs will remain below a 25 percent threshold. In the appendix, we present the results of a sensitivity analysis for both parameters; housing market and hurdle rate.

\section{EMPIRICAL RESULTS}

\section{Measuring accessibility}

With the model developed in the previous section, we are able to assess the accessibility of the homeownership market for different categories of households, including first-time buyers. As a start, we show in Table 2 the accessibility results for all households recently on the market - in terms of their affordability ratio and competiveness indicator. Later in this paper we will zoom in on changes over time and differentiate the results by housing market.

In comparison with other recent buyers, both indicators show some negative deviations for firsttime buyers. Both the affordability ratio is lower and the competiveness indicator higher. However, these differences are relatively minor and not unexpected given their general lack of housing equity they can put forward ${ }^{6}$. Finally, the category households typecasted as would-be-buyers ${ }^{7}$

\footnotetext{
${ }^{6}$ Movers from the rental sector were somewhat better off, mainly because their income is higher as were their savings, but even they were no match for the group movers who beat them in terms of income and wealth. 
show very distinct patterns: their affordability ratio is less than half of other groups, while the number of competitors on the market - competing for 'their' set of affordable houses - is twice as high. In other words, these potential buyers are simply forced out of the market. Recall that this group equals approx. 20 percent of total demand by non-homeowners for owner-occupied dwellings; a volume that remained constant over time. Given the profile of these households - incl. an extreme low average income $€ 1,300$ - it is debatable whether to take their ambitions, preferences, serious.

\section{The Change of Positions over Time}

As discussed above, the combination of both indicators can be used to typify the prevailing market condition for first-time buyers, and other categories of buyers. Here, low affordability and high competition lead to an inaccessible housing market for new entrants, while the opposite signals bigh accessibility. A high affordability ratio in combination with high competition amongst homeowners shows quantitative shortages; i.e. apparently, the housing market is affordable but the available stock is scarce. Normally, quantitative shortages will induce higher house prices and more supply, although the elasticity might not be very high. Finally, qualitative shortages may occur in a situation in which both affordability and competition is low, a situation that eventually will lead to lower house prices. Therefore, we can expect both situations - quantitative and qualitative shortages - to be just temporal phenomena.

We estimated for each individual on the market both his/her affordability of the dwellings on offer and the level of competition between households. By combining both, we are able to measure for each individual his/her 'position' on the regional housing market. Our approach enables us to assess whether the housing market can be typified as being low or high accessible for an individual household. In Figure 3, we present the results of that analysis: the share of households classified by the four 'positions' discussed above. We have repeated the analysis for

\footnotetext{
${ }^{7}$ Would-be-buyers are tenants that indicate in the surveys that they have tried and failed to buy a home during the preceding two years.
}

Page $\mid 15$ 
1985, and 1995. This way Figure 3 gives us not only an overview of the accessibility of regional housing markets today, but it gives us also additional information on the changing position of first-time buyers over the years. The results indicate that in the last decades, the accessibility of the homeownership sector became increasingly under pressure and that first-time buyers are loosing ground. The relative position of first-time buyers on the housing market has worsened over the years. In Figure 3, this can be seen by the shift from the category 'high accessibility' to 'low accessibility'. Over the years also the category 'quantitative shortages' has doubled, indicating that supply is lacking and not, that households' income falls short to succeed on the homeownership market.

More in general, it seems that it is not affordability that limits access to homeownership markets for first-time buyers. The affordability ratio has decreased over the years rather modestly, which is due to the effects of financial innovation, which has made mortgage loans cheaper over time. Most of the loss in accessibility is due to the changes in the level of competition between buyers on the housing market; the competiveness indicator had nearly doubled over the years from 0.81 in 1985 to 1.55 in 2006. So, while many first-time buyers and policy-makers alike, point to high house prices as the prime cause of inaccessible housing markets, this may be considered as a myth. It is not house prices that matter here, but a general lack of supply. Although our analysis cannot reveal why perceptions of households are so erroneous, one may easily hypothesise that increased quality demand $^{8}$ and some serious regional variations may be important grounds for those faulty perception.

\section{Regional Variations}

Finally, given the wide variety of profiles that is to be found among first-time buyers - for instance in terms of age, household size, and last but not least across regions - we might expect that the accessibility differs along these lines. Our analysis proofs us right, given that the affordability rises

\footnotetext{
${ }^{8}$ Housing demand can take on many forms, and are not easily measured. However, as illustration: in 1985 the average dwelling size of first-time buyers was $36 \mathrm{~m}^{2}$; anno 2006 this has grown to $96 \mathrm{~m}^{2}$, while there expressed preference amounted to $116 \mathrm{~m}^{2}$.
} 
from less than 77 percent for households aged below 34 to more then 87 percent for 55+households, while the competiveness indicator decreases over these ages from 1.53 to 1.26. We also finds that both the affordability ratio and competiveness factor is significantly "worse" for singles than for couples without children (68 percent versus 85 percent; 1.86 vs. 1.38). The most pervasive variations are however to be found across regions.

The results show a mix picture as can be seen in Figure 4, where both indicators are mapped out on a housing market level. In both maps a dark colour indicates low accessibility, i.e. a lower affordability, respectively high competition. Affordability across submarkets ranges from 87 percent in Groningen, in the North, to 70 in Den Bosch, in the Southeast. In the main urbanized Western parts of the Netherlands, affordability is approximately 80 percent. Note that in certain rural areas, close to the major cities, new supply on the market is relatively limited and quite expensive; hence, affordability may be substantially lower in those areas. At the same time, the relative high affordability ratio within urbanized areas is partly due to high number of multi-family dwellings, dwellings that may be less preferred. The competiveness indicator shows more variability; i.e. competition ranges from very low levels in the North to very high levels in the four main cities of the Netherlands. The maximum of 2.3 is found in Amsterdam while in certain rural areas in the North and East of the Netherlands, we document a competitiveness rate of less than one; indicating that more houses are on offer than demanded. The ongoing ageing of society leads in those areas to a depopulation and hence, competition is low (and will decline further).

Both maps indicate that accessibility has a strong regional dimension and secondly, that in highly competitive housing markets (e.g. in cities like Amsterdam and Utrecht), households will move to other regions with less competition. Over time, this leads to a ripple effect, in which gradually, low accessibility is spread over to neighbouring housing markets; a process that is well documented in the literature with respect to, for instance, house prices (e.g. Meen, 2001).

Page $\mid 17$ 


\section{SUMMARY AND DISCUSSION}

This paper analyzed the accessibility of the homeownership market for first-time buyers. We were able to profile these first-time buyers in comparison to other subgroups on the housing market and to examine whether and how the position of these buyers has shifted. To analyse these trends, we developed two indicators: on the demand side of the housing market, we employed an affordability measure to determine the portion of dwellings on sale that fit within the budget of first-time buyers. We also capture the supply side of the market by measuring competition amongst buyers.

Why do households, the media and policy-makers assume that the position of first-time buyers is weak and has weakened over the years? Part of the answers is that they are right. Our analysis shows that the position of first-time buyers is indeed relatively weak. However, this it inherent to the fact that first-time buyers need to contend with older, richer buyers that have already build some housing equity during the housing career. In addition, their position has diluted over the past years. However, this decline in the first-time buyers' position is relatively modest and has destabilized housing markets in the Netherlands. Nevertheless, in the perception of the most stakeholders, things seem to become much worse. Part of the answer lies into two factors. Firstly, regional analysis showed that the variation is huge and in certain 'popular' housing markets the probability of success for first-time buyers is low and indeed became much lower over the years (e.g. Amsterdam). Secondly, indications are that there seems to be a mismatch in terms of quality in some of the more 'fashionable' housing markets. Preferences of consumers may simply not be matched by the local housing supply; leaving some homeowners with a second-best, yet affordable, house.

Finally, how will these trends develop in the future? Nobody knows for sure, but house prices in the Netherlands are stabilizing, while the supply of owner-occupied dwellings increases, both as a result of newly built and the sale of rental dwellings. To date, the Dutch economy is still growing. So, gradually the position of first-time buyers should improve.

Page $\mid 18$ 


\section{REFERENCES}

Andrew, M. and G. Meen (2003), Housing transactions and the changing decisions of young households in Britain: the Microeconomic evidence, in Real Estate Economics 31 (1), pp. 117 38

Ásberg, P. (1999), Housing decisions of young Swedish adults, in Journal of Housing Economics 8 (2), pp. $116-143$

Boelhouwer, P. (2002), Trends in Dutch housing policy and the shifting position of the social rented sector, in Urban Studies 39 (2), pp. 219 -236

Boelhouwer, P. (2005), The incomplete privatization of the Dutch housing market: Exploding house prices versus falling house-building output, in Journal of Housing and the Built Environment 20 (4), pp. $363-378$

Boehm, T. P. (1993), Income, wealth accumulation, and first-time homeownership: an Intertemporal analysis, in Journal Housing Economics 3 (1), pp. 16 - 30

Bogdon, A.S. and A. Can (1997), Indicators of local housing affordability: Comparative and spatial approaches, in Real Estate Economics 25 (1), pp. 43 - 80

Bourassa, S.C. (1996), Measuring the affordability of homeownership, in Urban Studies 33 (10), pp. $1867-77$

Bourassa, S.C., D.R. Haurin, J.R. Haurin and P.H. Hendershott (1994), Independent living and home ownership: an Analysis of Australian youth, in Australian Economic Review 107 (3), pp. 29 $-44$

Department of Housing, Urban Development and the Environment (2006), Housing needs survey 2006, MVROM: The Hague

Engelhardt, G.V. (1994), House prices and the decision to save for down payments, Journal of Urban Economics 36, pp. 209-237

Hancock, K.E. (1993), 'Can pay? Won't pay' or economic principles of 'affordability', in Urban Studies 30 (1), pp. 127 - 145

Haurin, D.R., P.H. Hendershott and D. Kim (1994), Housing decisions of American youth, in Journal of Urban Economics 35 (1), pp. 28 - 44

Haurin, Donald R., Patric H. Hendershott, and Susan Wachter (1997), Borrowing Constraints and the Tenure Choice of American Youth, Journal of Housing Research 8, pp. 137-154.

Linneman, P.D. and I.F. Megbolugbe (1992), Housing affordability: Myth or reality?, in Urban Studies 29 (3/4), pp. 369 - 392

Ortalo-Magné, F. and S. Rady (1999), Boom in, bust out: Young households and the housing price cycle, in European Economic Review 43 (10), pp. 755 - 766

Meen, G. (2001), Modelling spatial housing markets: Theory, analysis and policy, Springer: Berlin

Paris, C. (2007), International perspectives on planning and housing affordability, in Housing Studies $22(1)$, pp. 1 - 9 
Quigley, J.M. and S. Raphael (2004), Is housing unaffordable? Why isn't it more affordable?, in Journal of Economic Perspectives 18 (1), pp. 191 - 214

Renes, G., M. Thissen and A. Segeren (2006), Betaalbaarbeid van koopwoningen en het ruimtelijk beleid (Affordability of Housing and Spatial Policy), The Hague: NAi/RPB

Weicher, J.C. (1977), The affordability of new homes, in AREUEA Journal 5, pp. 209 - 226.

Weicher, J.C. (1978), The new home affordability, equity, and housing market behavior, in AREUEA Journal 6, pp. 395 - 416 
Table 1| Some characteristics of first-time buyers on the Dutch housing market (2006)

This table presents summary statistics on various characteristics of first-time-buyers, for the year 2006. Here we present the mean income, housing costs, house price, and some mortgage related ratio on a household level. The data originate from the 2006 Housing of the Dutch Ministry of Housing. We present the same information for the average household in both the rental and ownership sector, for the sake of comparison. The next expenditure ratio divides the net housing costs by net income.

\begin{tabular}{|c|c|c|c|}
\hline & \multicolumn{2}{|l|}{ Households (all) } & \multirow[b]{2}{*}{ First-time buyers } \\
\hline & Homeownership sector & Rental sector & \\
\hline Monthly net household income & $€ 3,055$ & $€ 2,000$ & $€ 2,732$ \\
\hline Monthly net housing costs & $€ 429$ & $€ 441$ & $€ 545$ \\
\hline House prices & $€ 303,761 *$ & -- & $€ 220,385$ \\
\hline Loan to value ratio & 56 percent & -- & 94 percent \\
\hline Loan to income ratio & 2.57 & -- & 4.02 \\
\hline Net expenditure ratio & 16.12 percent & 24.13 percent & 22.55 percent \\
\hline Number of households & $3,829 \mathrm{k}$ & $3,301 \mathrm{k}$ & $259 \mathrm{k}$ \\
\hline
\end{tabular}

Source: Housing need survey 2006 
Figure 1| Distribution of the maximum loan capacity of first-time buyers and house prices of recent sold properties (Netherlands, 2006).

In this figure, we plot the distributions of the maximum loan capacity of Dutch first-time buyers versus the distribution of house prices of recently sold houses. Both distributions relate to the Dutch market for the year 2006, and based on data that originate from the 2006 Housing Need Survey of the Dutch Ministry of Housing. Both maximum loan capacity and house prices are in logarithm. The total number of dwellings on offer is equal to number to successful first-time buyers minus the group would be buyers, estimated as 79-thousand

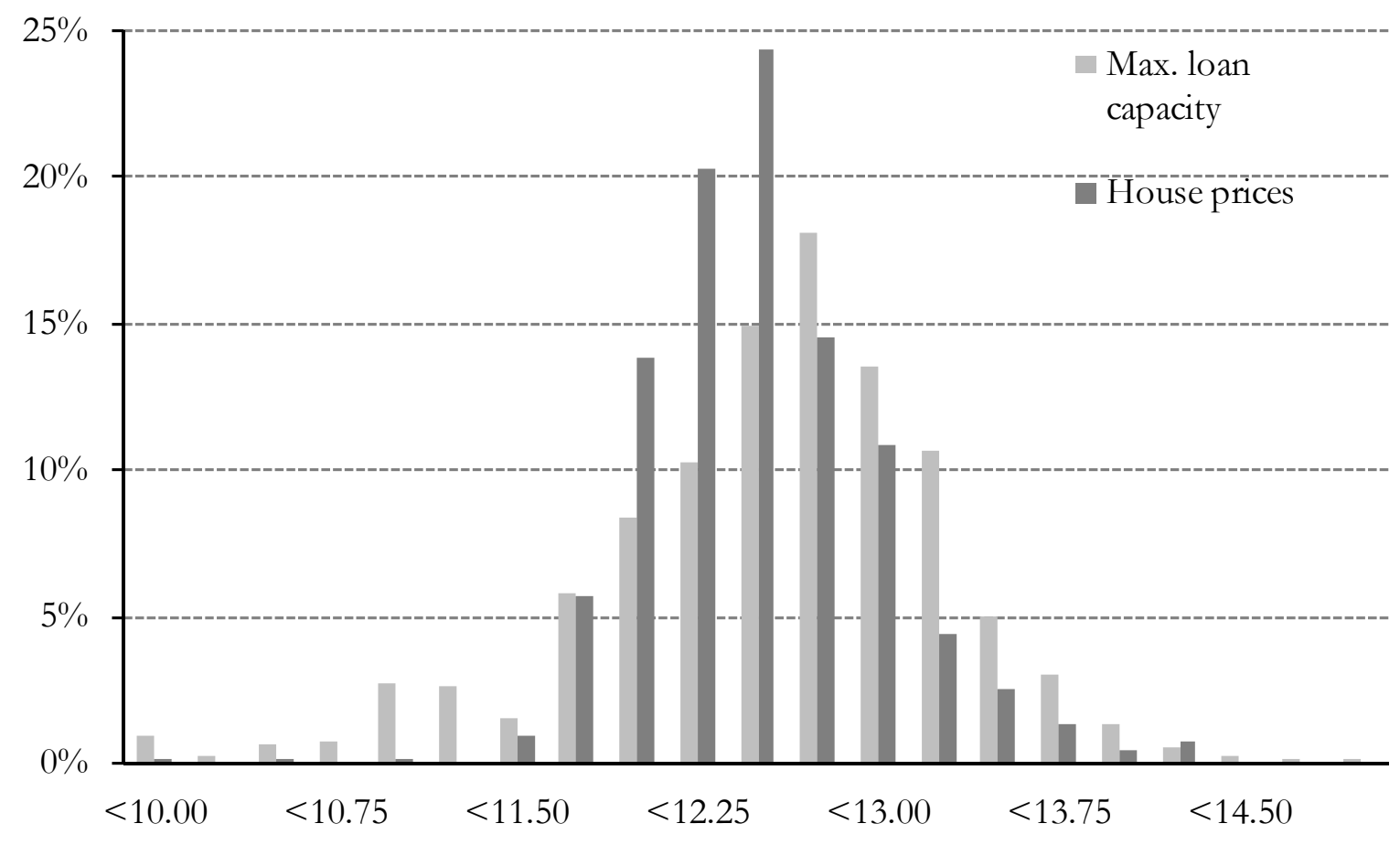


Figure 2| Derivation of the affordability ratio and the competiveness indicator

In the figures below, we plot distributions of maximum loan capacity in grey versus the distribution of house prices of recently sold houses in black. The total overlap between both distributions represents the share of affordable houses, as part of the total recent supply. All figures are indicative and are not based on real numbers. In panel A we demonstrate the household $I$, with a certain income level and loan capacity, we be able to afford all houses within section $\mathrm{ABC}$. This household will however need to compete for these houses with all households in section ACDE, that are in a similar financial position. In fact, household $I$ will also need to compete with households that are in section AFGE, since they are in a better financial position, but might as well be looking for a home in section ABC. Panel A, therefore demonstrates us the concept of accessibility, which combines affordability (section ABC) with competitiveness (section CFGD). In sections B and C we indicate within this framework the position of 'first-timebuyers' and 'recent buyers', by positioning their distribution of maximum loan capacity.

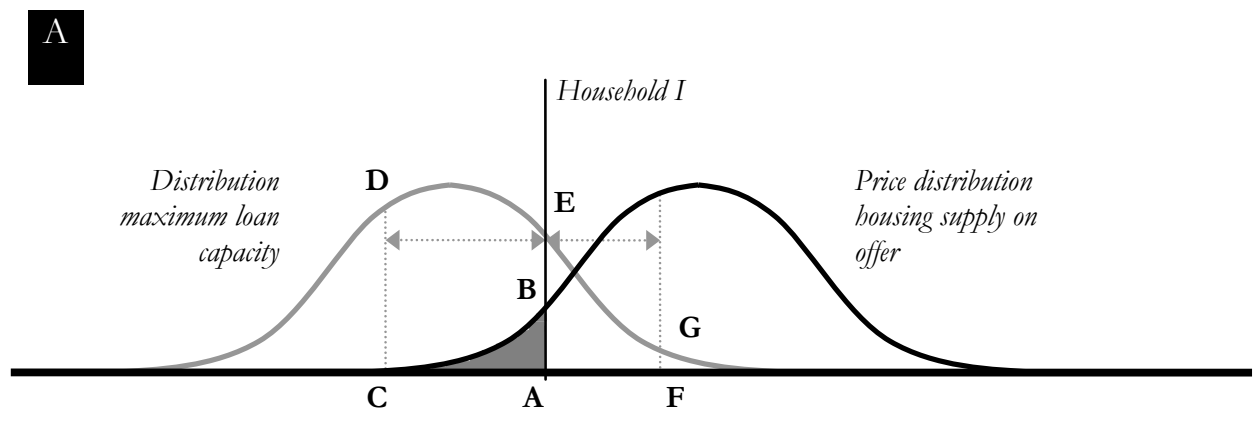

Affordability low, competiveness high, e.g. first-time buyers
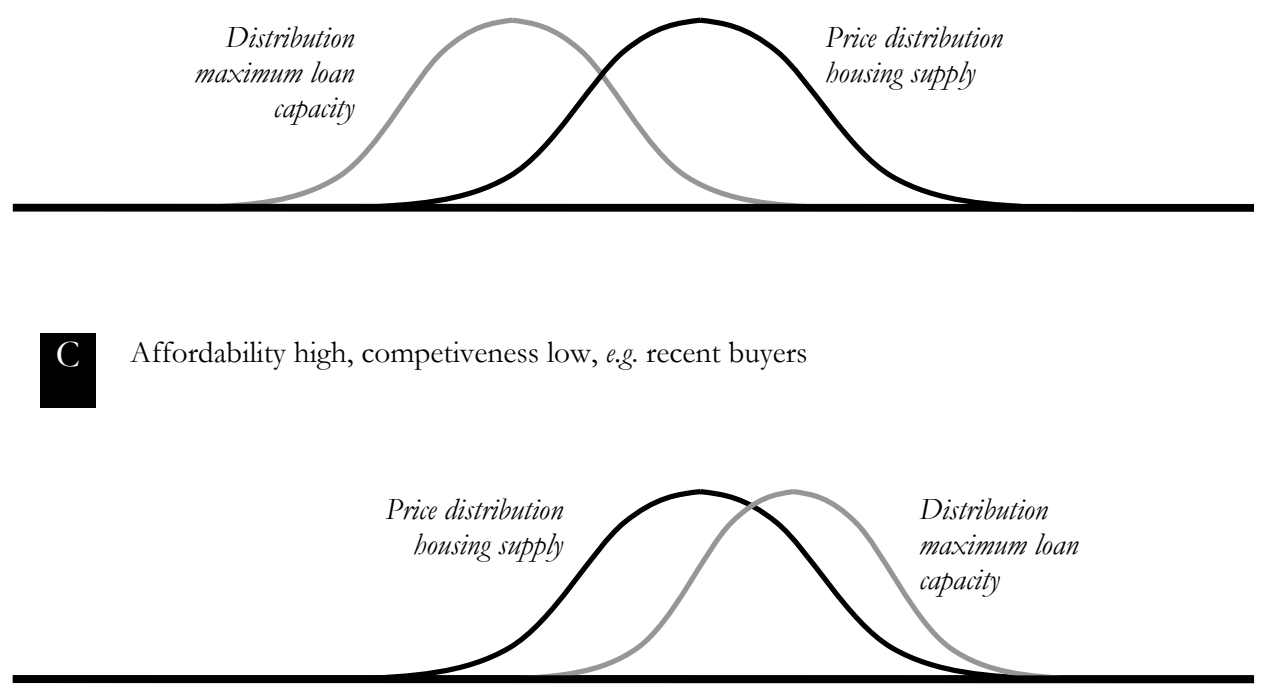
Table 2| The affordability ratio and competiveness indicator for different subgroups on the homeownership market (Netherlands, 2006)

In this table, we present the results of our empirical analysis of the affordability ratio and competitiveness indicator for various groups within the Dutch housing market for the year 2006. The affordability ratio is scaled from 0 to 1 , with high values indicating a high share of affordable supply. The competiveness indicator is scaled from 0 to $\infty$; if the competiveness indicator is 1 , the market is in equilibrium, a higher value indicates increased competition between buyers and vice versa.

\begin{tabular}{|c|c|c|c|c|}
\hline & \multicolumn{2}{|c|}{ First-time buyers } & \multirow[b]{2}{*}{ Recent buyers } & \multirow[b]{2}{*}{ Would be buyer } \\
\hline & Former tenants & New to the market & & \\
\hline \multicolumn{5}{|c|}{ Affordability ratio } \\
\hline - Mean & 0.81 & 0.76 & 0.86 & 0.40 \\
\hline - Median & 0.88 & 0.85 & 0.93 & 0.34 \\
\hline - Variance & 0.20 & 0.23 & 0.18 & 0.28 \\
\hline \multicolumn{5}{|c|}{ Competiveness } \\
\hline - Mean & 1.54 & 1.58 & 1.40 & 3.18 \\
\hline - Median & 1.40 & 1.35 & 1.28 & 2.20 \\
\hline - Variance & 0.83 & 1.01 & 0.72 & 2.58 \\
\hline
\end{tabular}

Source: Housing need survey 2006 (authors' calculations) 
Figure 3| Assessing the accessibility of the homeownership market: the changing position of

$$
\text { first-time buyers }(1985,1995 \text {, and 2006) }
$$

In this figure, we classify the accessibility of the housing markets from the perspective of first-time buyers into four categories. The combination of low affordability and low competition is referred to as a 'quantitative shortage'. When affordability is high while competition is low, we associate the market with 'high accessibility'. In the reverse situation, when affordability is low and competition is high, we speak of 'low accessibility'. Finally, the combination of high affordability with high competition is considered as a 'qualitative shortage'. For the cut-off point of classification we use the average affordability rate (in 2006) of $79 \%$ and a competiveness indicator of 1.00 for every household in our panel.

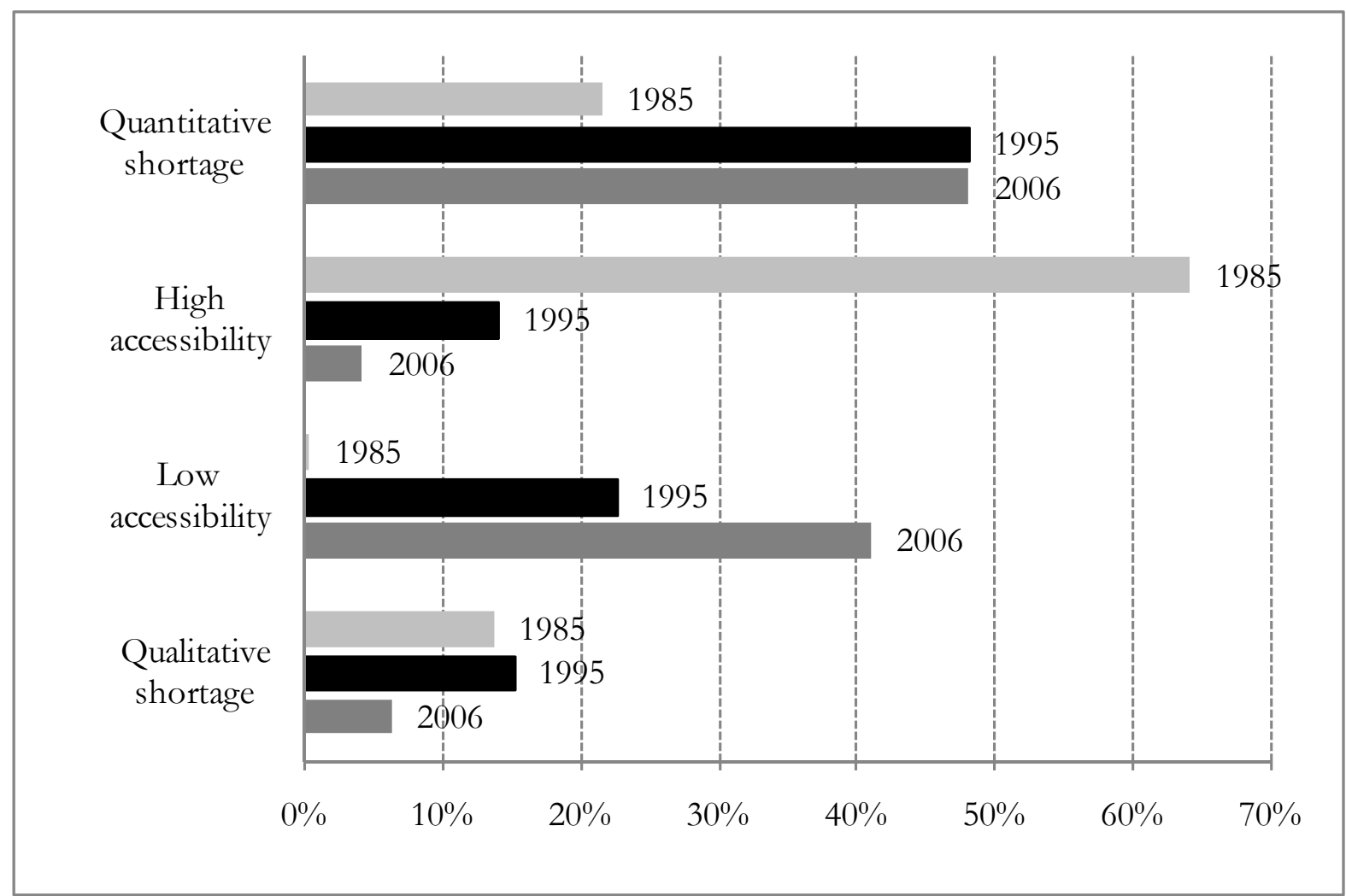

Source: Housing need survey 1985, 1995, and 2006 (authors' calculations) 
Figure 4| Affordability and competitiveness rates across regions, 1985 and 2006

In these figures, we present the average levels of affordability and competitiveness on a local housing market level for the years 1985 and 2006. These figures illustrate the regional dispersion of the accessibility of the housing market and the change in both affordability and competitive pressure over the sample period. In both cases we use dark colours to indicate a loss in market position, which is a relatively low level of affordability and high level of competition. The categories are set relative to the total average of 1985.
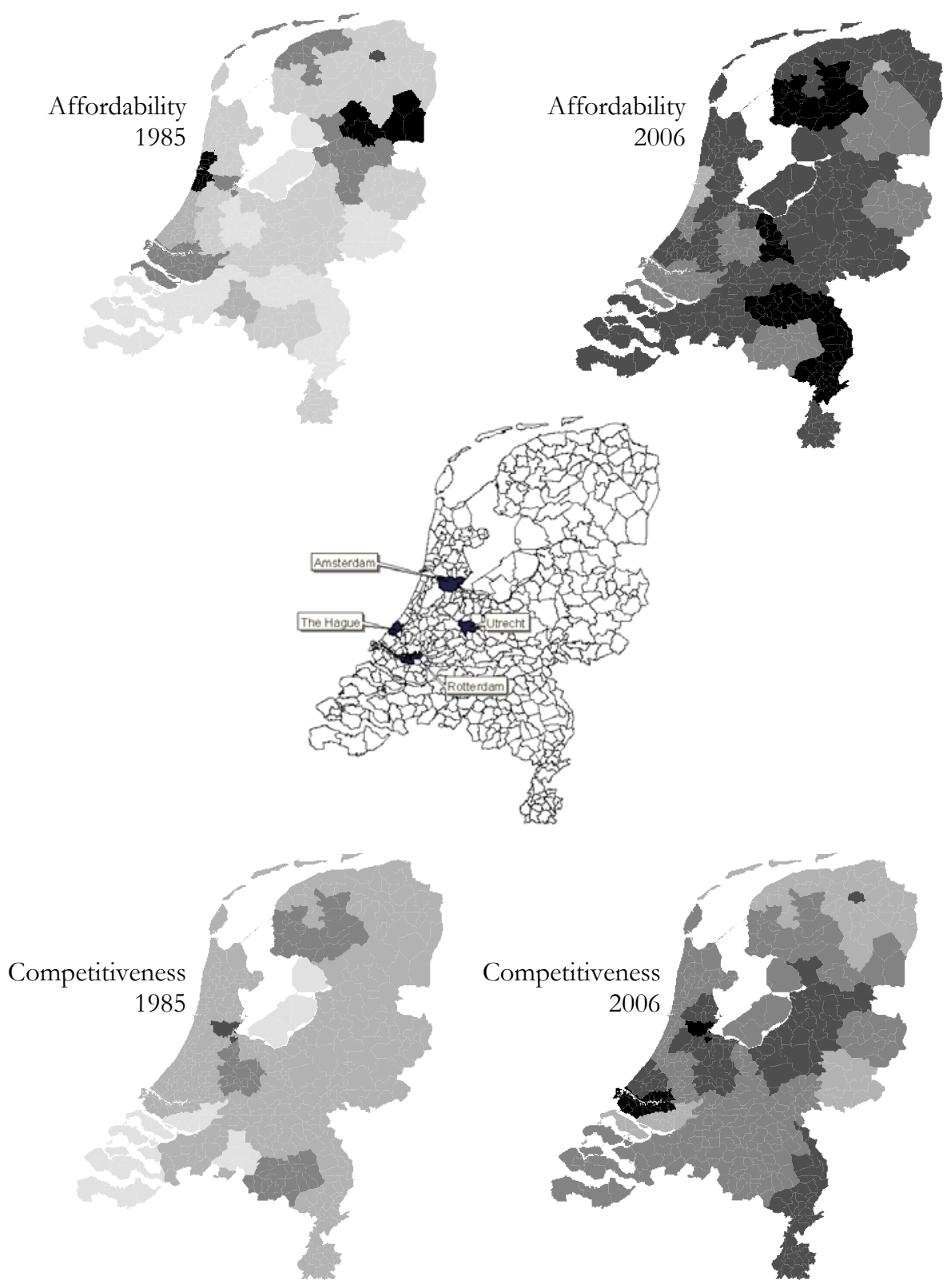


\section{Appendix | Sensitivity Analysis}

In section 3, when discussing the different indicators, we stated that both were depending on the aggregation level, i.e. the regional scale $D$, and secondly, on the hurdle rate $\left(\delta_{b}\right)$. Here, in this Appendix, we show to what extent the results presented in the paper depend on the exact parameter value. The result of a sensitivity-analysis is presented in Table 3; showing off the affordability ratio and competiveness indicator for different level of the aforementioned parameters.

Table 3 The affordability ratio and the competiveness indicator, by hurdle rate and regional level

Affordability ratio Competiveness ratio

\section{Hurdle rate}

$\begin{array}{lll}-35 \text { percent } & 0.72 & 1.36 \\ -25 \text { percent } & 0.67 & 1.45 \\ -15 \text { percent } & 0.53 & 2.06\end{array}$

\section{Regional level}

- National

- Regions (4)

- Housing market (31)
1.36

2.06

Note: $\quad$ The grey shaded rows represent the reference category for the analysis in section 4; calculated with a reduced sample-size $(1 / 10$ the $)$

The affordability ratio is positively related to the hurdle rate and negatively related to the competiveness indicator. Changing the regional scale to higher levels leads only to a modest increase in the affordability ratio, however, competition will be substantially fiercer. Finally, note that we analyzed, in the paper the accessibility of the housing market for first-time buyers on (1) a housing market level $(D=31)$ and (2) with the maximum hurdle rate $\left(\delta_{b}\right)$ set on 35 percent. 